\title{
STEM education and outcomes in Vietnam: Views from the social gap and gender issues
}

\author{
Quan-Hoang Vuong, Thanh-Hang Pham, Trung Tran, Thu-Trang \\ Vuong, Manh-Cuong Nguyen, Khanh-Linh P. Nguyen, Viet- \\ Phuong La, Manh-Toan Ho
}

United Nations' Sustainable Development Goals 4 Quality Education has highlighted major challenges for all nations to ensure inclusive and equitable quality access to education, facilities for children, and young adults. The SDG 4 is even more important for developing nations as receiving proper education or vocational training, especially in science and technology, means a foundational step in improving other aspects of their citizens' lives. However, the extant scientific literature about STEM education still lacks focus on developing countries, even more so in the rural area. Using a dataset of 4967 observations of junior high school students from a rural area in a transition economy, the article employs the Bayesian approach to identify the interaction between gender, socioeconomic status, and students' STEM academic achievements. The results report gender has little association with STEM academic achievements; however, female students (aa_Sex[2] = 2.83) appear to have achieved better results than their male counterparts (aa_Sex[1] $=2.68$ ). Families with better economic status, parents with a high level of education $(\beta b(E d u M o t)=0.07)$, or non-manual jobs (aa_SexPJ[4] = 3.25) are found to be correlated with better study results. On the contrary, students with zero $(\beta b($ OnlyChi $)=-0.14)$ or more than two siblings $(\beta b$ (NumberofChi) $=-0.01)$ are correlated with lower study results compared to those with only one sibling. These results imply the importance of providing women with opportunities for better education. Policymakers should also consider maintaining family size so the parents can provide their resources to each child equally.

Keywords: STEM education; gender gap; socioeconomic status; social disparities; SDGs; developing country; rural area.

JEL Classifications: I24; I25; 015

CEB Working Paper N²0/003

March 2020

Université Libre de Bruxelles - Solvay Brussels School of Economics and Management Centre Emile Bernheim 


\title{
STEM education and outcomes in Vietnam: Views from the social gap and gender issues
}

Quan-Hoang Vuong ${ }^{1,2}$, Thanh-Hang Pham ${ }^{3,4}$, Trung Tran ${ }^{5}$, Thu-Trang Vuong ${ }^{6}$, Manh-Cuong Nguyen ${ }^{7}$, Khanh-Linh P. Nguyen ${ }^{1,8}$, Viet-Phuong La ${ }^{1,8}$, Manh-Toan Ho ${ }^{1,8}$

${ }^{1}$ Centre for Interdisciplinary Social Research, Phenikaa University, Yen Nghia Ward, Ha Dong District, Hanoi 100803, Vietnam

${ }^{2}$ Centre Emile Bernheim, Universite Libre de Bruxelles, 50 Ave. F.D. Roosevelt, Bruxelles B-1050, Belgium

${ }^{3}$ Faculty of Management and Tourism, Hanoi University, Km9, Nguyen Trai Road, Thanh Xuan, Hanoi 100803, Vietnam

${ }^{4}$ School of Business, RMIT Vietnam University, Hanoi, 100000, Viet Nam

${ }^{4}$ Faculty of Basic, Vietnam Academy for Ethnic Minorities, Hanoi 100000, Vietnam

${ }^{5}$ Sciences Po Paris, 27 Rue Saint-Guillaume, 75007 Paris, France

${ }^{7}$ Faculty of International Studies, Hanoi University, Km9, Nguyen Trai Road, Thanh Xuan, Hanoi 100803, Vietnam

${ }^{8}$ AISDL, Vuong \& Associates, 3/161 Thinh Quang, Dong Da District, Hanoi 100000, Viet Nam

Corresponding Author: Quan-Hoang Vuong (qvuong@ulb.ac.be or hoang.vuongquan @phenikaauni.edu.vn)

\begin{abstract}
United Nations' Sustainable Development Goals 4 Quality Education has highlighted major challenges for all nations to ensure inclusive and equitable quality access to education, facilities for children, and young adults. The SDG4 is even more important for developing nations as receiving proper education or vocational training, especially in science and technology, means a foundational step in improving other aspects of their citizens' lives. However, the extant scientific literature about STEM education still lacks focus on developing countries, even more so in the rural area. Using a dataset of 4967 observations of junior high school students from a rural area in a transition economy, the article employs the Bayesian approach to identify the interaction between gender, socioeconomic status, and students' STEM academic achievements. The results report gender has little association with STEM academic achievements; however, female students $\left(\alpha_{\mathrm{a}_{-} \operatorname{Sex}[2]}=2.83\right)$ appear to have achieved better results than their male counterparts $\left(\alpha_{a_{-} \operatorname{Sex}[1]}=2.68\right)$. Families with better economic status, parents with a high level of education $\left(\beta_{\mathrm{b}(\text { EduMot })}=0.07\right)$, or non-manual jobs $\left(\alpha_{\mathrm{a}_{-} \operatorname{SexPJ}[4]}=3.25\right)$ are found to be correlated with better study results. On the contrary, students with zero $\left(\beta_{b \text { (Onlychi) }}=-0.14\right)$ or more than two siblings $\left(B_{\mathrm{b}(\text { NumberofChi) }}=-0.01\right)$ are correlated with lower study results compared to those with only
\end{abstract}


one sibling. These results imply the importance of providing women with opportunities for better education. Policymakers should also consider maintaining family size so the parents can provide their resources to each child equally.

Keywords: STEM education; gender gap; socioeconomic status; social disparities; SDGs; developing country; rural area.

JEL Code: 124; 125; 015.

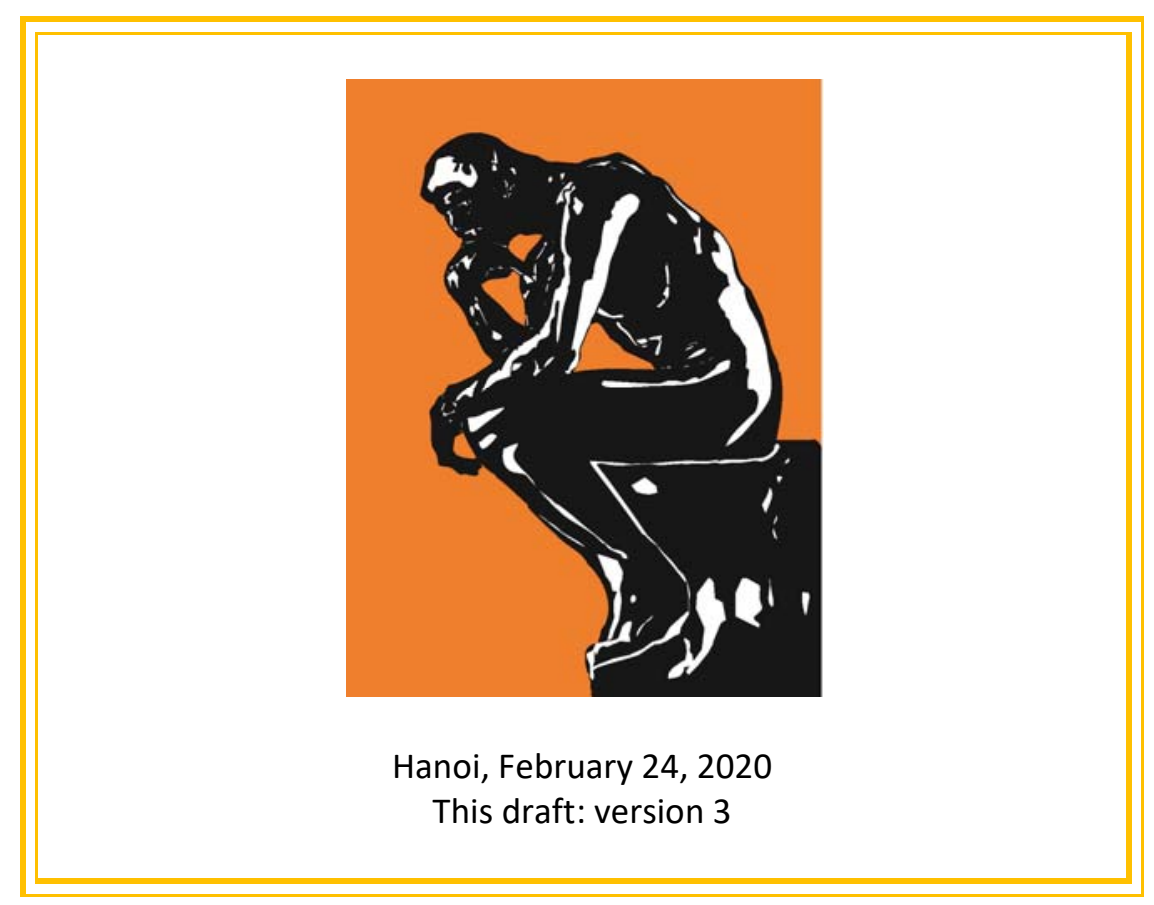




\section{Introduction}

In modern society, science is acknowledged as playing a vital role in fostering technological advancement and sustainable economic development (Pavitt, 1996; Xie, 2014; Xie et al., 2015). Moreover, the new age of computational power and entrepreneurship (Vuong, 2019b; Trung Tran et al., 2019) necessitates the emphasis on science and technology to tackle global challenges of the human race (Skorton, 2019). Considering the current pressing issues - namely climate change, health disparities, food shortage, and others - one may say that science, technology, engineering, and mathematics (STEM) disciplines had become of greater importance than ever.

From another perspective, the developing world has long lagged regarding research and technological innovation (Arauco et al., 2014; Villarroel-Mareño and Ergueta, 2012). According to UNESCO Science Report (2015), in 2013, high-income economies account for $69.3 \%$ of global expenditure on research and development, while this figure is merely $30.4 \%$ and $0.3 \%$ for middle-income and low-income economies respectively (UNESCO, 2015). Ideally, these latter would be seeking to boost their STEMrelated research so that they could match the senior academic landscape among developed countries with a prolonged and prosperous history of research and development (Kremer et al., 2013; Serpa et al., 2018; Eilks and Hofstein, 2014; Knamiller, 1984). One means to this end - and not exclusive to this end, either - would be to develop STEM education, which proved to be both useful and challenging (Ferreira et al., 2019). In fact, in a list of the Sustainable Development Goals (SDGs), the United Nations has highlighted the importance of high-quality education as foundational to sustainable development (United Nations). Developing STEM-related education, especially for developing countries, would be a direction that fits a path towards targets 4.4, 4.5, and 4.7 of this goal for Quality Education. As education is not only about programs and teachers but also learners, boosting students' motivation to study STEM subjects and disciplines is critical in ensuring quality and inclusive education. To do this, it is argued that researchers need to take into account a diverse set of factors that can help clarify the attainment and motivation of students in the STEM education domain (Burušić et al., 2019).

Among developing nations, Vietnam provides an exotic case of the relationship between social factors and STEM education with its high economic growth rates and the top position in the Programme for International Student Assessment (PISA) ranking of average scores in Math, Science, and Reading. Despite low national average income, Vietnam is among the countries with the largest share of household contribution to total education spending and the highest level of effectiveness of government expenditure spent on education (Takaoka, 2019). Observing this, some might point to the Vietnamese culture, namely in aspects such as the historical normalization of lifelong studies, as well as the traditions which value knowledge-seeking and the social prestige of being a "man of letters." As such, an examination of demographic factors and students' performance in STEM domains would shed light on the intertwining between socioeconomic status (SES) and academic achievement in similar transitioning sociocultural contexts. This research focuses on investigating factors affecting STEM education to provide the robust groundwork for policy-making in national education in Vietnam (Vuong et al., 2018a; Vuong et al., 2018b), and progress equity in education and science (Vuong, 2019c; a; 2018).

\section{Literature review}

Students' academic performance could be associated with the attributes of their social settings (Xie et al., 2015). Various studies have examined socioeconomic factors affecting students' cognitive 
development and academic aptitudes in numerous subjects, including STEM. A substantial body of literature stated the important role of socioeconomic background including family income (Xie et al., 2015), parental educational level (Noble et al., 2015; Kendler et al., 2015) and occupation together with birth order (Hotz and Pantano, 2015) (Moakler Jr and Kim, 2014). Social disparities in academic performance also include the gender gap, which suggests that the effects of SES could vary depending on the gender of students.

\section{Gender and STEM academic performance}

There has yet to be consensus in the literature on the "gender gap" among students in STEM-related subjects, in terms of academic achievement. Various studies stated that female students match or outperform their male counterparts in math and science, based on their grades, in both elementary and secondary school (Kenney-Benson et al., 2006; Shettle et al., 2007). With a sample of 518 students (265 girls, 253 boys) in Illinois, Kenney-Benson (2006) pointed out that girls outperform boys in math in terms of their grades (collected from their school records) but not their achievement tests scores (collected from results in standardized tests). To explain this, the author argued that girls do not experience an edge over boys in self-efficacy, a factor that appears to play a larger role in determining children's performance on achievement tests than in the classroom. In fact, girls' advantage over boys in terms of their grades intensified over time (Kenney-Benson et al., 2006). A study conducted by The National Assessment of Educational Progress (NAEP) consisting of 15,400 eighth-graders from 600 schools in the United States in 2018 indicated that female students scored higher than their male peers in Technology and Engineering Literacy overall (Progress, 2018). Female students also scored higher than their male peers in more content areas and practices in 2018 compared to 2014 (Progress, 2018). Breda, T. \& Napp, C. (2019) used the data from 300,000 students in 64 countries to explain that the gender gap in mathrelated areas can be justified mainly by female students' comparative advantage in reading(Breda and Napp, 2019).

Conversely, several empirical studies showed an advantage of male students over their female peers (Penner and Paret, 2008; Robinson and Lubienski, 2011). Penner and Paret (2008) conducted a study covering more than 18,000 students in the United States and collected data as these learners progressed from kindergarten to fifth grade (Penner and Paret, 2008). Findings from this research indicated that boys were significantly more represented in the upper extreme of the math's achievement distribution and when combined with SES factors and that this higher attainment was largest in families characterized by a high level of parental education (Penner and Paret, 2008). Data from the Early Childhood Longitudinal Study, Kindergarten Class of 1998-1999 also revealed that the academic achievement gap was observed among boys and girls starting from first grade and persisted until eighth grade (Robinson and Lubienski, 2011). This gender gap is argued to constrain female students' access to advanced math courses and college entry in science disciplines (Anaya et al., 2017). In general, being a woman has consistently been found as a robust negative determinant for STEMrelated issues (Betz and Hackett, 1981; Chavez, 2001; Fouad, 1995; 2007; Sax, 1994); subsequently, in STEM fields, women are significantly underrepresented, devalued and underpaid (Cech and Blair-Loy, 2019).

\section{Socioeconomic status (SES) and STEM academic performance}

In general, family characteristics, especially SES, have strong associations with math and science performance, interest in majoring in STEM, and completion of a STEM degree (Xie et al., 2015). The 
STEM achievement gap among students with various SES has been empirically documented in almost every nation (Burušić et al., 2019). Throughout schooling, participation and achievement in STEM subjects are consistently different between those from low and high socioeconomic backgrounds (Miller and Kimmel, 2012; Schneider et al., 1997). For example, using the OECD's PISA test scores of 94,050 students from 406 schools in 15 European countries in 2003, Martins and Veiga (2010) found socioeconomic related inequality in mathematics scores, with students coming from a household of higher SES having clear advantages over their less fortunate peers (Martins and Veiga, 2010). Socioeconomic factors represent between $14.9 \%$ and $34.6 \%$ of the overall inequality in education (Martins and Veiga, 2010). In the case of the United States, vast inequalities exist in education achievement due to family SES. College students from lower-income backgrounds usually had lower assignment grades, test scores, and attendance than those from higher-income contexts (Caro et al., 2015; Reardon, 2011b; Sirin, 2005; Ziol-Guest and Lee, 2016). Compared to notable and persistent achievement gaps due to racial differences, this gap of SES can be two to three times as large (Reardon, 2011b). For example, in a regional US longitudinal sample with 2264 students from 12 school districts in Michigan, Caro et al. (2015) indicated that family SES is positively related to academic achievement in school with main determinants identified as father's education, occupation, and mother's education (Caro et al., 2015). In a meta-analysis review, Sirin (2005) examined a sample of 101,157 students from 6,871 schools located in 128 school districts gathered from 74 independent samples (Sirin, 2005). The results showed a medium to strong SES-achievement relation. This relation, however, is moderated by the unit, the source, the range of SES variable, and the type of SES-achievement measure. The relation is also contingent upon school level, minority status, and school location(Sirin, 2005). The study notably explained that family with middle and high SES have better levels of income and education, therefore can provide children with parental support and exposure to STEM-related experiences, thus nurturing an early interest, and likely contributing to self-confidence and ambitions in STEM (Archer et al., 2012; Harackiewicz et al., 2012; Sjaastad, 2012; Turner et al., 2004). Remarkably, family income has been the most intensely studied SES factor impacting the educational gap (Pfeffer, 2018). Reardon (2011) reported the steadily increasing gaps in educational achievement between students from low-income and high-income backgrounds in more than 50 years (Reardon, 2011a). In the United States, the gaps in achievement among poor and advantaged students are substantial, with students from low-income families consistently scoring well below average, regardless of ethnicity or race (Bergeson, 2006). For example, a study conducted by Sum and Fogg (1991) found that poor students are ranked in the 19th percentile on assessments while students from a mid-upper income family are ranked in the 66th percentile on assessments (Sum and Fogg, 1991).

Academic achievement, especially in STEM, is necessary to graduate high school, enter college, and pursue fast-growing and lucrative STEM careers (Rozek et al., 2019). It is also considered a lever to bring opportunities to students coming from financially disadvantaged backgrounds. However, these students often perform poorly in the subjects, leading to disadvantages in career opportunities and perpetuating the vicious circle of intergenerational poverty(Reardon, 2011b; Carnevale et al., 2013).

Moreover, different characteristics of family structure have been found to affect educational results irrespective of SES, for example, single-parent headship (Astone and McLanahan, 1991; Kim, 2011) or the number of siblings (Blake, 1989; Downey, 1995; Steelman et al., 2002). In particular, a substantial body of research demonstrates the effects of family size and birth order on education (Hotz and Pantano, 2015; Black et al., 2005; Booth and Kee, 2009; Cheng et al., 2013). Various studies had 
provided strong evidence on the association between birth order and academic performance, as well as analyzed the different mechanisms that led to this correlation (Behrman and Taubman, 1986; Black et al., 2005; Booth and Kee, 2009). Based on the theory about population restrictions on economic development, researches have hypothesized about the adverse impacts of family size on child quality (Becker and Lewis, 1973; Becker and Tomes, 1976). This may be due to the assumption that quality tradeoff happens when the number of children increases (Qian, 2009). However, it appears that the opposite is also possible under several circumstances, which means that there exist economies of scale in raising children (Qian, 2009). For instance, children may share clothes and textbooks with their sisters and brothers. In this case, quantity can complement quality.

Understanding this trade-off is relevant and of particular importance to policymakers in developing nations, since many governments have tried to limit population growth as a means to boost human capital investment (Qian, 2009). For instance, the world's two most populous nations - China and India have been trying various policies to restrict family size. Nevertheless, the empirical evidence regarding this tradeoff between quantity and quality is conflicted. Studies have found no effect of even a positive effect of family size on child outcomes in Israel (Angrist et al., 2005; Angrist et al., 2010), Korea (Lee, 2008), the United States (Kessler, 1991), China(Guo and VanWey, 1999) and Africa (Gomes, 1984).On the contrary, this impact has been reported to be negative in other countries such as France(Goux and Maurin, 2005), the U.S.(Hotz and Pantano, 2015), Taiwan (Cheng et al., 2013) and China (Rosenzweig and Zhang, 2009). From a slightly different angle, Hotz \& Pantano (2015) argued that there is a significant association between early birth order and better academic performance by studying a sample of children of 6,283 American female respondents in the National Longitudinal Survey of Youth 1979 (Hotz and Pantano, 2015). First-borns generally perform better than second-borns; second-borns better than third; and the performance decreases as the birth order climbs. This effect is found to be consistent in all family size (Hotz and Pantano, 2015). With a sample of 290588 adolescents aged $15-16$ years old in Taiwan, Cheng et al. (2012) also found a decline in student results when birth order advanced, and this impact was evident in Mathematics, Science as well as Mandarin (Cheng et al., 2013). This inverse relationship between academic outcomes and birth order was also reported to be consistent among all levels of parental education, although more evident impacts were found in higher-educated households than lower-educated ones (Cheng et al., 2013). However, it is stated that an important gap exists in the literature, which is the lack of understanding about the effects of increasing the number of children from one to two (Qian, 2009). When parents tend to prefer smaller household size, this margin is of increasing importance (Qian, 2009).

An important SES factor is parental occupation which could influence children's performance and interest in STEM subjects in various ways (Anaya et al., 2017), including more financial investments in both classroom and extra-curricular activities, type of educational activities encouraged, or simply the example that parents set for their children (Anaya et al., 2017). For example, parents with occupations in STEM fields are already inclined towards such subjects, thus - whether consciously or not - cultivating in the child an interest in STEM subjects; and creating more incentives for the child to pick STEM-related aspirations amongst other endeavors by offering mentorship and removing barriers or uncertainty related to STEM occupations (Moakler Jr and Kim, 2014). Nollenberger and Rodriguez Planas (2017), using data from the PISA study with 11,527 second-generation immigrants coming from 35 different countries of ancestry and living in 9 host countries, state that parental opinions on gender social norms impact the motivation of their children in learning, and this links with different achievement in math and 
science examination scores (Rodríguez-Planas and Nollenberger, 2018). The work by Anaya et al. (2017) also shared the same finding and further confirmed that having at least a parent or guardian having a STEM-related job is correlated with a higher likelihood of being on the highest percentiles of the math test score distribution (Anaya et al., 2017). Similarly, various studies have concluded that parents' belief in the importance of math and science in later education and employment leads to higher math performance in children as well as more enrolment in these subjects in high school (Giannelli and Rapallini, 2017; Harackiewicz et al., 2012). These beliefs and attributes are potentially very different between those in managerial or administrative positions versus those who are employed in manual labor.

Besides, parental education has been established as having a direct, positive, and long term impact on a student's educational accomplishment (Burušić et al., 2019). Kryst, Kotok, and Bodovski (2015) explored the data of five European countries from 1995 to 2011 and found a significant relationship between parental education and science achievement across all nations studied (Kryst et al., 2015). In another study, Davis-Kean (2005) examined a sample of 868 eight to twelve years old children (436 females, 433 males) in the United States and found that parental education and income were indirectly related to children's academic achievement through parents' beliefs and behaviors (Davis-Kean, 2005).

\section{Interaction between SES and student gender on STEM academic performance}

The link between SES and gender of students in affecting academic performance has been examined in several studies. In Anaya et al. (2017)'s research with a sample of 2158 children (about half males and half females) with their standardized tests score, girls present statistically significantly lower than average performance on the test (Anaya et al., 2017). Observed gender differences in math performance decline with parental occupation related to science. This parental occupation type also increases the likelihood for both genders to achieve test performance in the top percentiles, but the effect is larger for boys than for girls (Anaya et al., 2017).

Guo et al. (2019) also stated that gender differences in interest for STEM subjects are responsive to family influences (Guo et al., 2019). Parent modeling of STEM interests enables girls to envision themselves in counter-stereotypical STEM roles. The study used data from the 2015 Programme for International Students Assessment (PISA) with 38 countries comprising of 256968 participants. Results show that girls with either parent employed in STEM had significantly higher science interest compared with those without parents employed in STEM careers (Guo et al., 2019). On the other hand, students' academic success in STEM subjects is usually related to their interest, motivation, and engagement when taking those subjects (Eccles and Wigfield, 2002). This parental role-model effect was stronger in more socioeconomically developed countries(Guo et al., 2019).

The review suggests that the current body of literature about STEM education is mostly centered on the United States and other developed countries; therefore, researchers think that the developing world deserves special attention (Muindi and Tsai, 2017). Furthermore, the rural areas and their distinctive characteristics are still understudied in most samples of previous works. Consequently, in this study, we focus on investigating factors affecting STEM academic achievements in the rural area of a developing country.

Materials 
The study empirically explored a sample of over 5000 junior high students in a northern of Vietnam. The data was collected by conducting surveys at 16 junior high schools in Ninh Binh province, Viet Nam, from December 2017 until July 2018. The result is a comprehensive dataset of 4966 junior high students' and personal and household-related attributes such as reading habits, academic achievements, family financial condition, etc. The data is available in OSF (Vuong et al., 2019b). The following variables were used to explore the factors associated with students' STEM academic achievements:

- "EcoStt": Categorical variable indicating the economic status of students' families. Categories are coded as follows: 1 = poor; 2 = medium; 3 = rich;

- "EduMot" and "EduFat": Categorical variables representing parental education. Categories are coded as follows: 1 = under high school; 2 = high school; 3 = university; 4 = graduate school;

- "RankingF": Numerical variable indicating the birth order of the student;

- "NumberofChi": Numerical variable indicating the number of children in the family;

- "Sex": Categorical variable indicating the biological sex of the students, coded as: 1 = male; 2 = female;

- "CarFatGr" and "CarMotGr": Categorical variables indicating the father's and mother's profession, respectively. Categories are coded as: $1=$ non-manual labor; 2 = manual labor. In certain published versions of this dataset or analyses done on this dataset, you may find these same categories labeled as intellectual and labor, respectively. This is purely due to linguistic disparity and has no bearings on the substantial aspect of the data;

- "APS45": Continuous variable calculated as the average score of the student's most recent 45minute tests in STEM subjects: Maths, Physics, Chemistry (and Biology where applicable). Tests are graded on a scale of 0 to 10 with 10 being the highest score;

- "APS45ID": A recoded variable of APS45, with five categories as follows:

\begin{tabular}{|l|l|l|}
\hline Level & Meaning & Conditions \\
\hline 1 & Poor & "aps45" under 5 \\
\hline 2 & Average & "aps45" above or equal to 5 and under 7 \\
\hline 3 & Above Average & "aps45" above or equal to 7 and under 8 \\
\hline 4 & Good & "aps45" above or equal to 8 and under 9 \\
\hline 5 & Excellent & "aps45" above or equal to 9 and under or equal to 10 \\
\hline
\end{tabular}

Using the above variables, we constructed new variables for data analysis:

- "OnlyChi": Dichotomous variable indicating whether a student is an only child, coded as: $1=$ only child and $0=$ not an only child. The variable takes on the value 1 if and only if the variable "NumberofChi" = 1 and "RankingF" = 1.

- "ParentJob": Categorical variable calculated from "CatFatGr" and CarMotGr". The variable takes on three values: 1 = both parents are non-manual labor workers; 2 = one of the parents is a manual labor worker; 3 = both parents are manual labor workers.

- "SexPJ": Categorical variable created by grouping "ParentJob" and "Sex".

\begin{tabular}{|l|l|l|l|}
\hline & SexPJ & Sex & ParentJob \\
\hline 1 & $1 \_1$ & Male & both parents are non-manual labor workers \\
\hline
\end{tabular}




\begin{tabular}{|l|l|l|l|}
\hline 2 & $1 \_2$ & Male & one of the parents is a manual labor worker \\
\hline 3 & $1 \_3$ & Male & both parents are manual labor workers \\
\hline 4 & $2 \_1$ & Female & both parents are non-manual labor workers \\
\hline 5 & $2 \_2$ & Female & one of the parents is a manual labor worker \\
\hline 6 & $2 \_3$ & Female & both parents are manual labor workers \\
\hline
\end{tabular}

\section{Methods}

This research article aims to estimate student academic achievement based on school, grades, and SES of the family using Bayesian methods of statistical analysis. The no-pooling multi-level model was employed, taking into account the multi-level of the school and grade variables, along with varying intercepts with fixed effect covariates. The mathematical foundation that was used for building the model is as follows:

$$
\text { Oi alpha[xvarint }]+ \text { betaj * xji }
$$

In which $\mathrm{Oi}$ is the dependent variable, $x$ varint is the varying intercept, $x \mathrm{j}$ is the $\mathrm{j}^{\text {th }}$ independent variable.

Because $\mathrm{O}$ is a binomial variable; the distribution $\mathrm{O}$ is represented in the following formula:

$$
0 \sim \text { nomial(mu, sigma) }
$$

In which:

$$
\text { mui }=\text { alpha[xvarint }]+ \text { betaj }^{*} \text { xji }
$$

The full dataset of 4966 records was cleaned and resulted in a dataset of 4630 observations valid for data analysis. The new dataset was saved in the .csv format: STEM_model.csv for formal analysis in R. For certain analyses, the dataset was also subset into two groups: 2299 male and 2331 female students. The results from all three datasets will be presented. The analysis was done in $\mathrm{R}$ statistical software, using a BayesVL package (v0.9). The package is available in (La and Vuong, 2019), and similar applications of Bayesian analysis can be found in (Vuong et al., 2019a; Vuong et al., 2018a).

Based on the mathematical foundation and the data, we have the following formulation for assessing the factors associating with students' STEM academic achievements:

APS45ID b_EduMot_APS45ID * EduMot + b_EduFat_APS45ID * EduFat + 


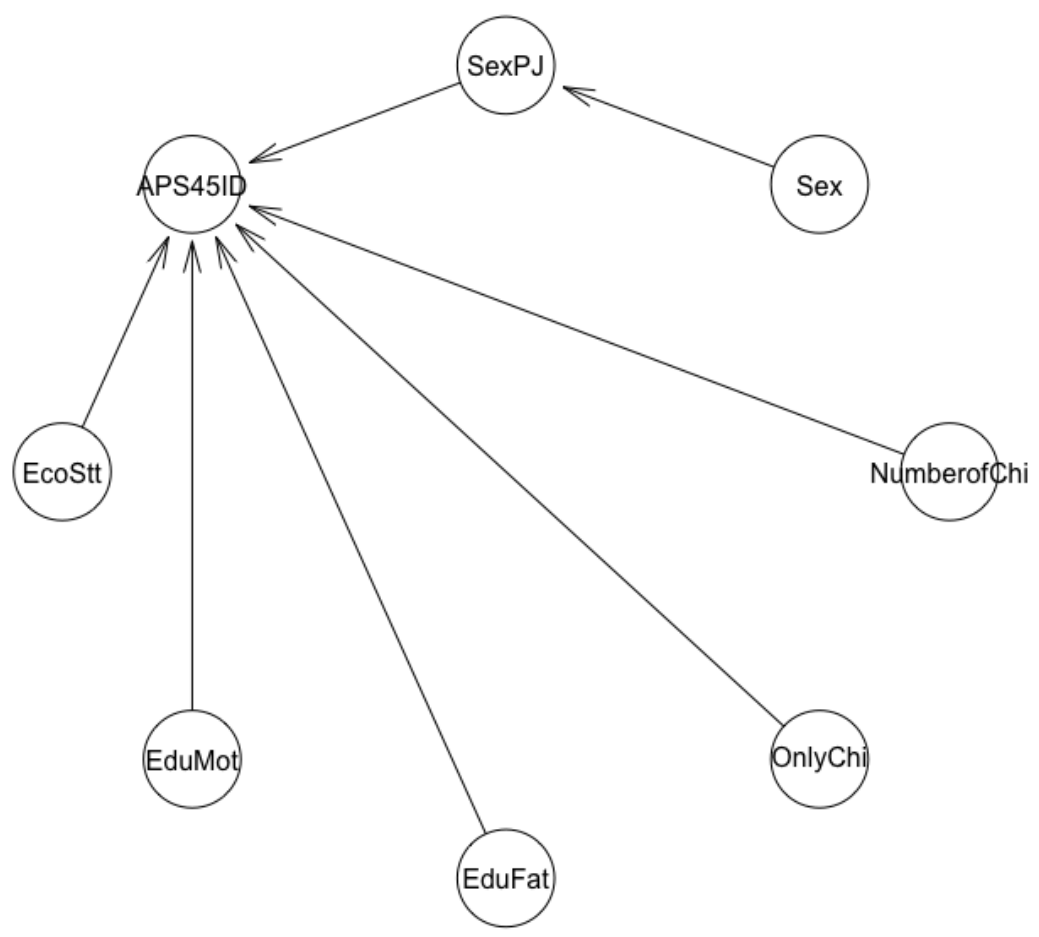

Figure 1. The Bayesian regression model.

The $\mathrm{R}$ code that was used to construct the model and the corresponding STAN code is available in Supplementary Information.

\section{Results}

The result of the model analysis is as follows:

> summary(model)

Model Info:

nodes: 9

arcs: 9

scores: NA

formula: APS45ID b_EduMot_APS45ID * EduMot + b_EduFat_APS45ID * EduFat + b_OnlyChi_APS45ID * (RankingF+NumberofChi $==2$ ? $1: 0)+$ b_NumberofChi_APS45ID * NumberofChi + b_EcoStt_APS45ID * EcoStt + a_SexPJ[SexPJ] 


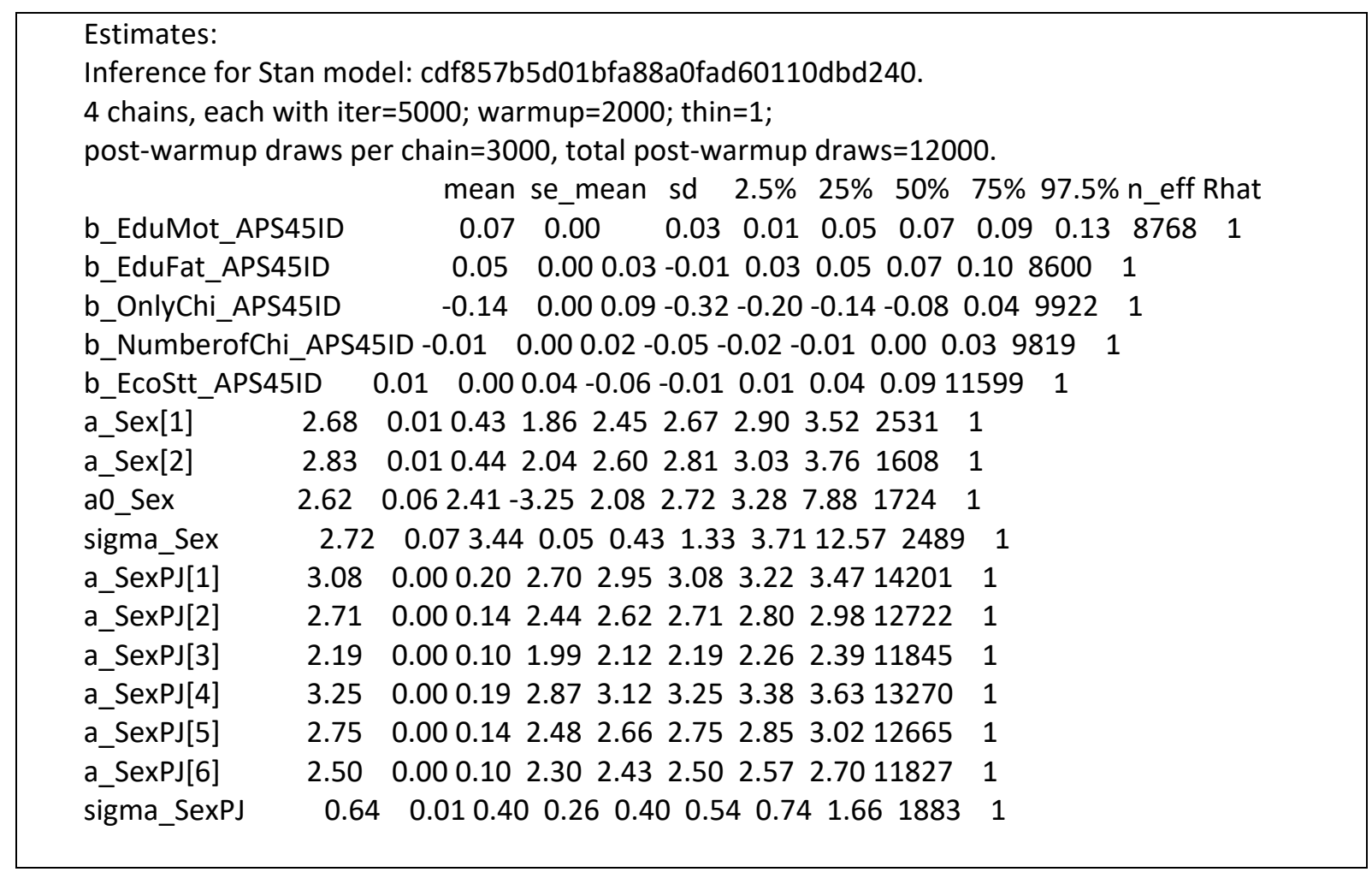

According to the model summary, the model has a good convergence because the effective sample size (n_eff) is above 2,000, and Rhat's values are one (1). The results give us the median potential scale reduction factor and its $97.5 \%$ quantile. We also get a multivariate potential scale reduction factor that was proposed by Gelman and Brooks. In the following section, the effect of each factor towards the STEM achievement of the student will be presented. Visual diagnostics of the MCMC chains are shown in Figure 2. There are four component chains in each chain shown in Figure 2, each of which has 5000 iterations. Overall, all chains are similar with no sight of divergent chains, which indicates the autocorrelation phenomenon and reflects the Markov property of the distribution. 

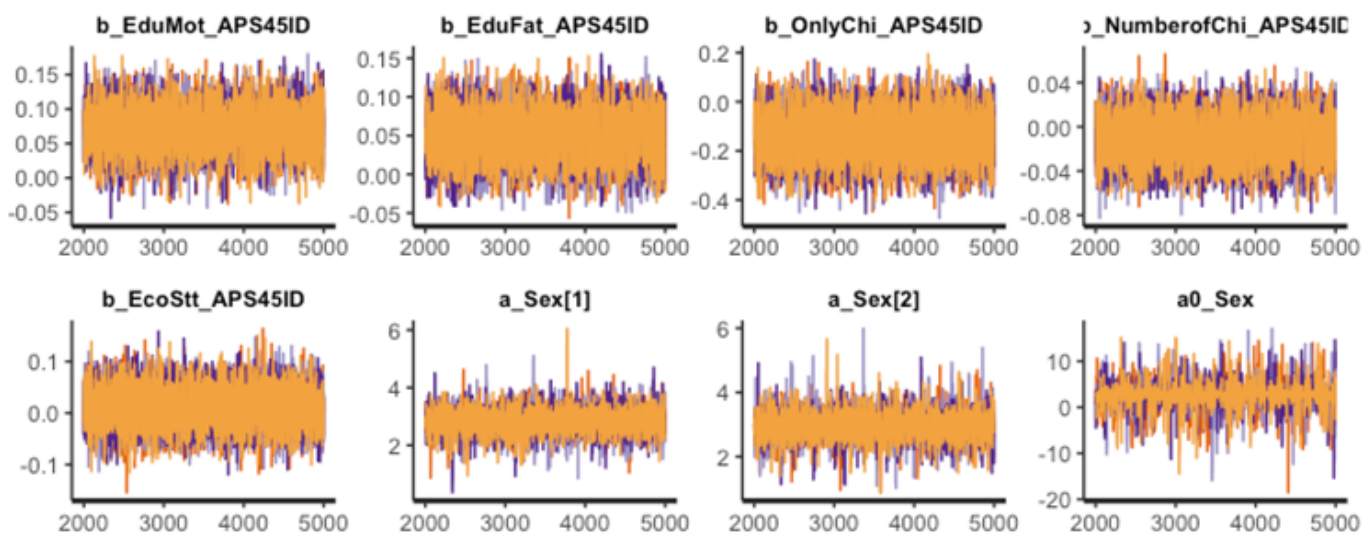

a0_Sex

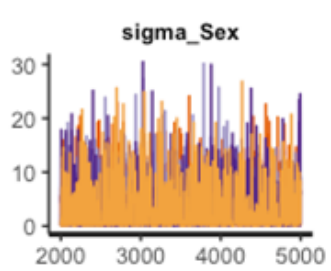

a_SexPJ[1]

a_SexPJ[2]

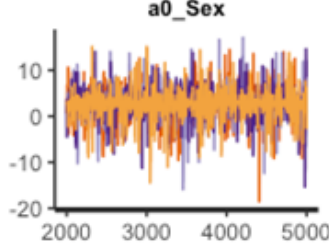

chain
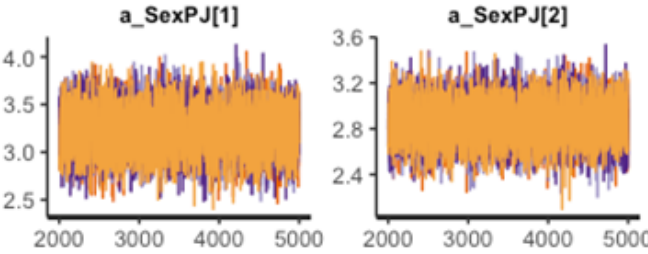

a_SexPJ[3]

- 1

a_SexPJ[4]

a_SexPJ[5]

a_SexPJ[6]
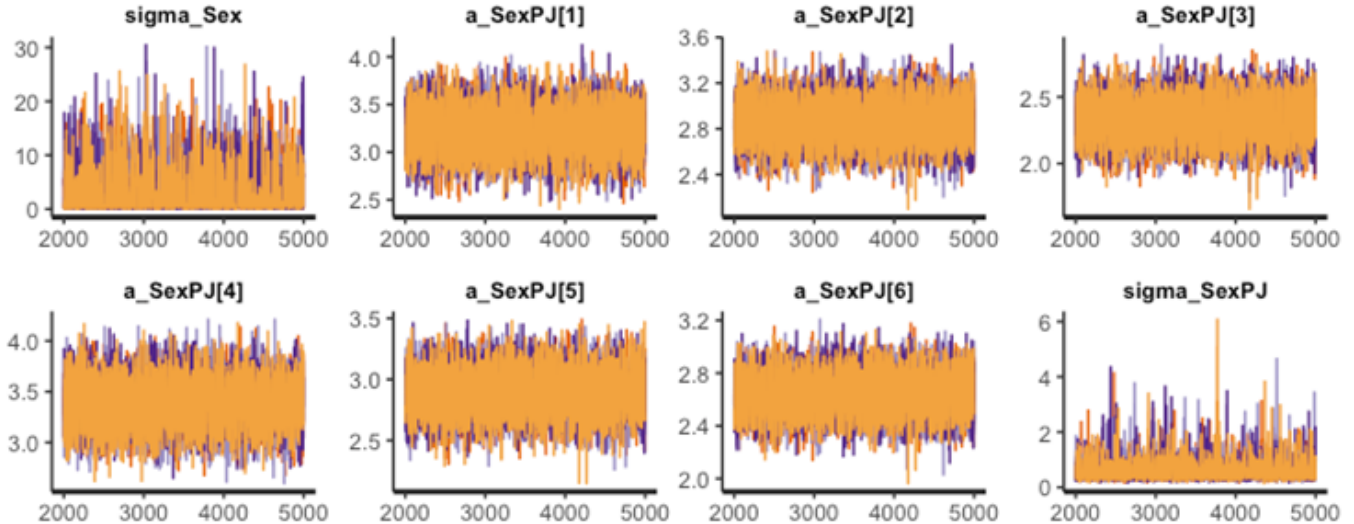

Figure 2. The visual representation of the MCMC chains

\section{Biological sex}




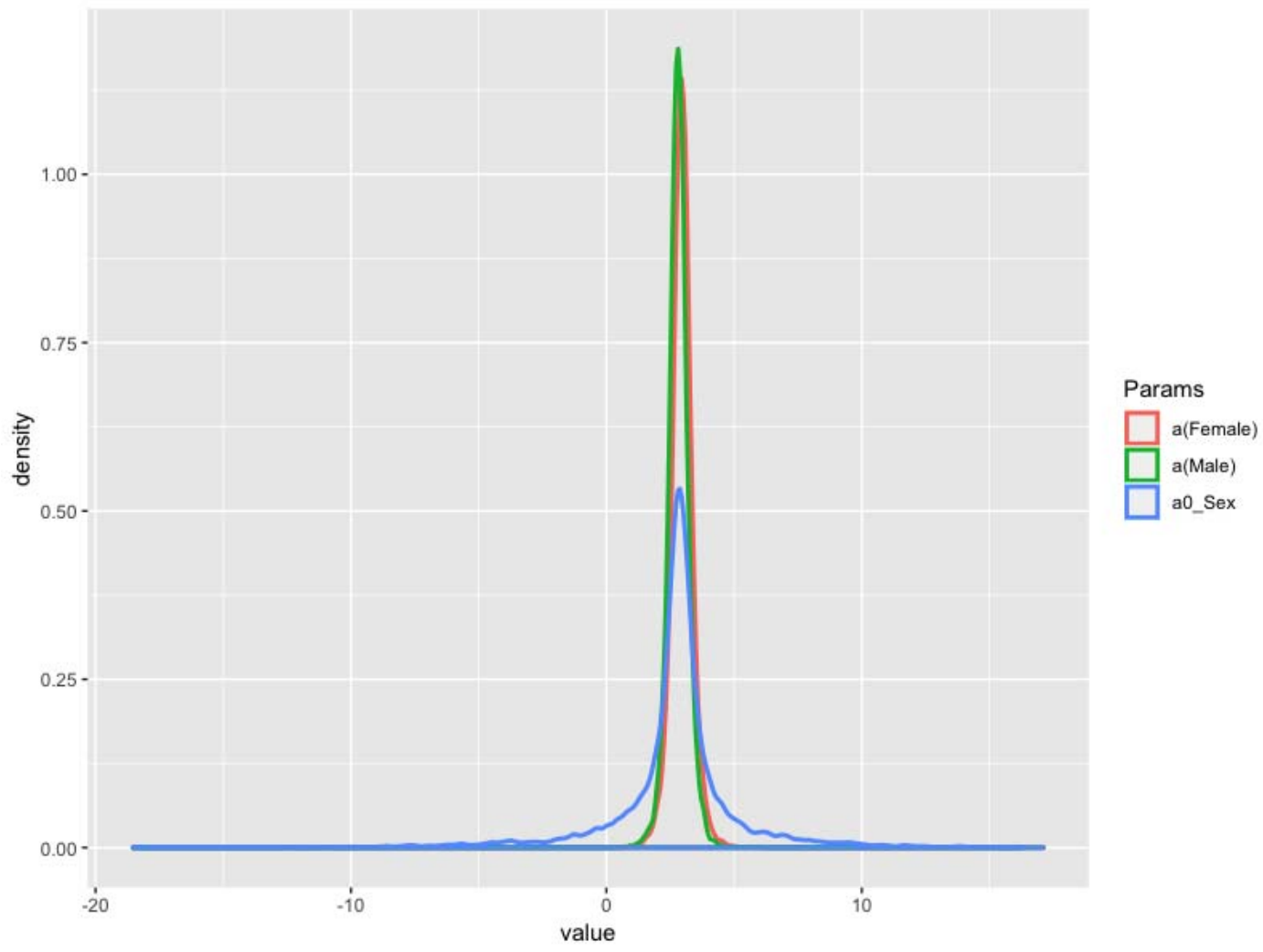

Figure 3. Distribution of coefficients of variables that indicate the biological sex of the students.

Firstly, the distribution of coefficients of variables that indicate the biological sex of the students is shown in Figure 3. The coefficient value of male students $\left(\alpha_{a_{-} \operatorname{Sex}[1]}=2.68 \mathrm{~m}\right)$ is slightly lower than the value of female students, with $\alpha_{a_{-} \text {Sex[2] }}=2.83$. The coefficient suggests the difference in STEM academic achievement, which is associated with sex, is not evident.

Number of children 


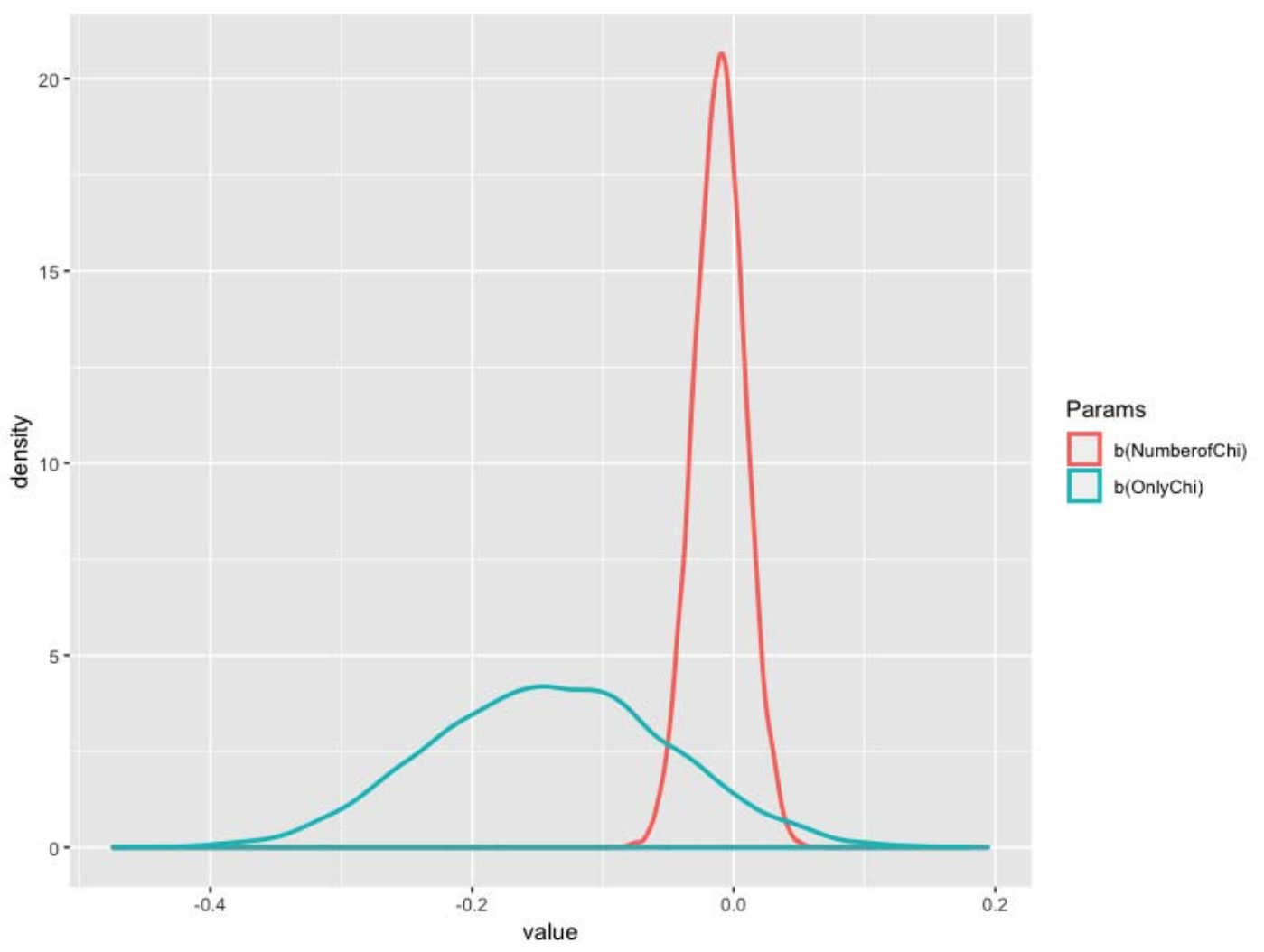

Figure 4. Distribution of coefficients of $b$ (NumberofChi) and b(OnlyChi)

Figure 4 presents the association between the number of children in the family and students' results. Both the coefficients, for the number of children and the case of the only child, are negative, $B_{b \text { (Numberofchi) }}$ $=-0.01$ and $B_{\mathrm{b}(\text { Onlychi) }}=-0.14$, respectively. The results suggest that both being the only child and having too many siblings negatively affect academic results.

\section{Parental education and economic status}




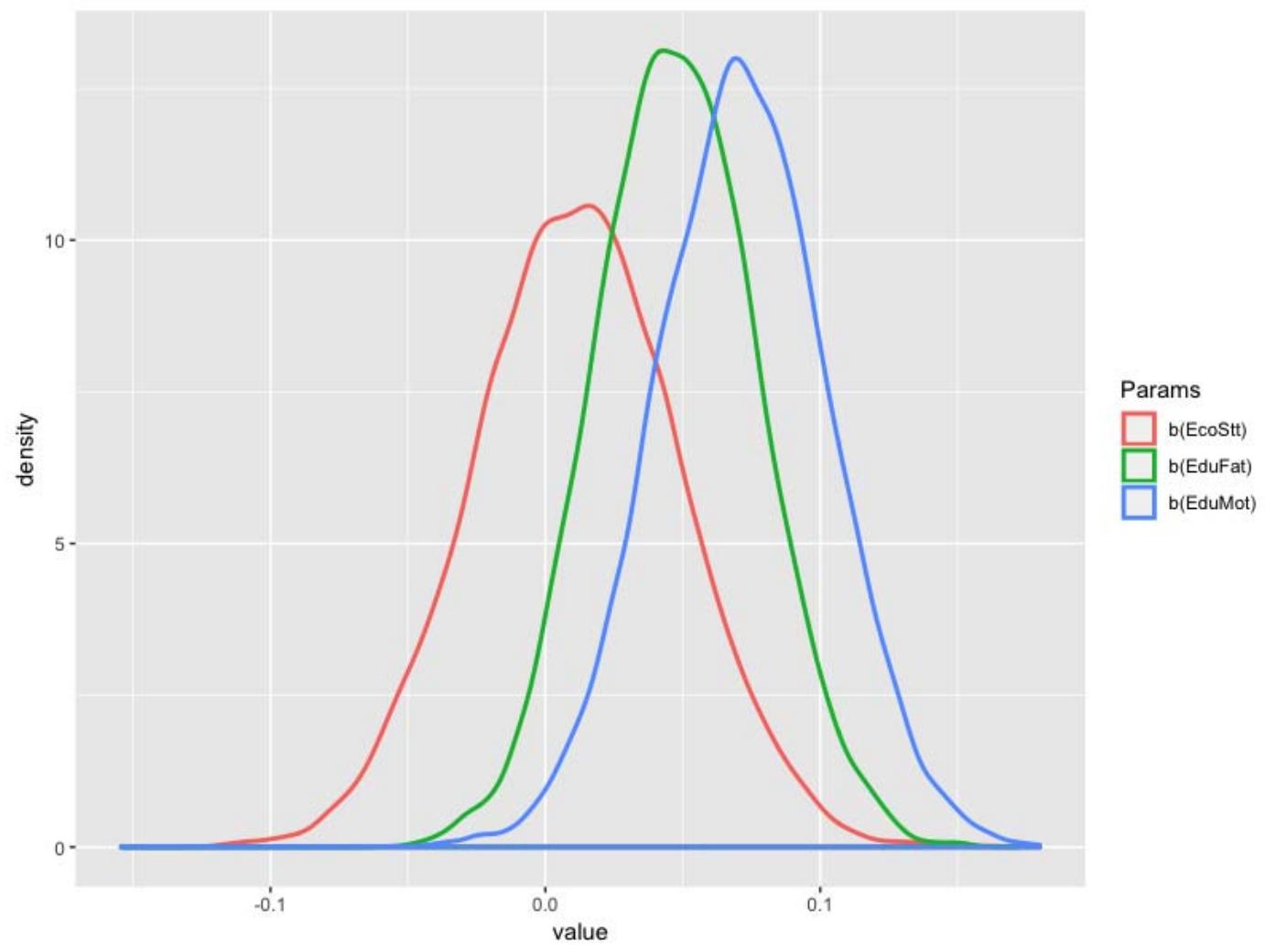

Figure 5. Distribution of coefficients of variables that indicate the economic status of the family and the education level of parents.

In Figure 5, the economic status, and the education level of both parents are presented. There is no coefficient distributed in the negative range, which suggests all three factors positively affect the STEM results. Taking a closer look at the educational level of the parents, the result suggests the higher the educational level of the parents, the higher the STEM results of the child. Notably, the educational level of the mother $\left(B_{\mathrm{b} \text { (EduMot) }}=0.07\right)$ is slightly higher than the educational level of the father or the economic status $\left(B_{\mathrm{b} \text { (EduFat) }}=0.05\right)$. 


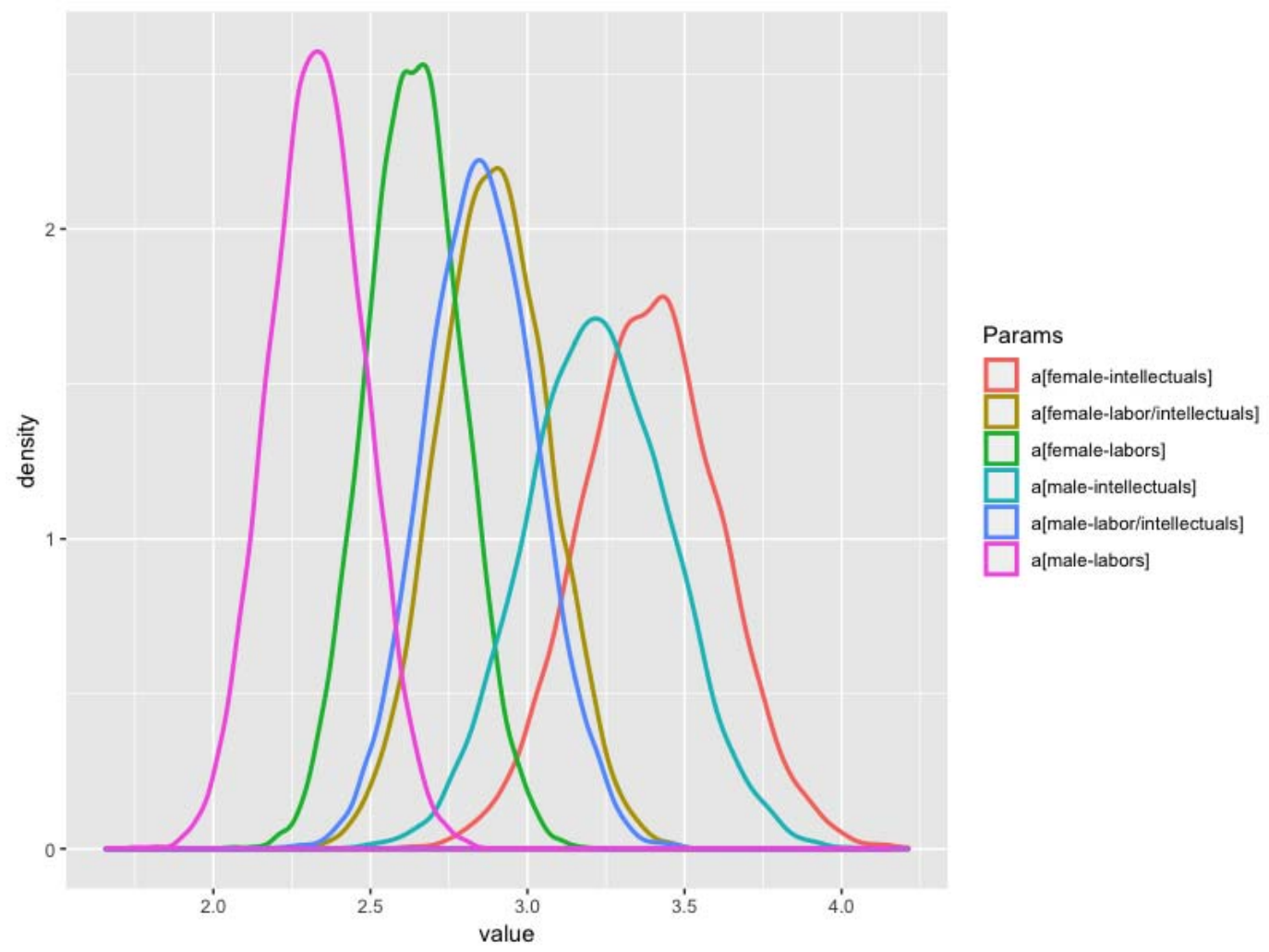

Figure 6. Distribution of coefficients of variables that indicate the occupation of parents, in line with students' biological sex.

When both parents have non-manual professions, the results of either male $\left(\alpha_{a_{-} \operatorname{SexP}[1]}=3.08\right)$ or female $\left(\alpha_{a_{-} \text {SexP[4] }}=3.25\right)$ are higher than when both parents work in manual labor $\left(\alpha_{a_{-} \text {SехP[[3] }}=2.19\right.$ and $\alpha_{a_{-} \text {SехP][6] }}=$ 2.50). Moreover, in each group of parents' jobs, female students often have better results than their male counterparts (see Figure 6).

\section{Prediction of a student's academic achievement based on the parent's occupation}

When designing the variables, we have coded the software to predict the outcome according to the values of the SexPJ variable. Thus, when we vary biological sex and parent occupation, the results are shown in Figure 6. 

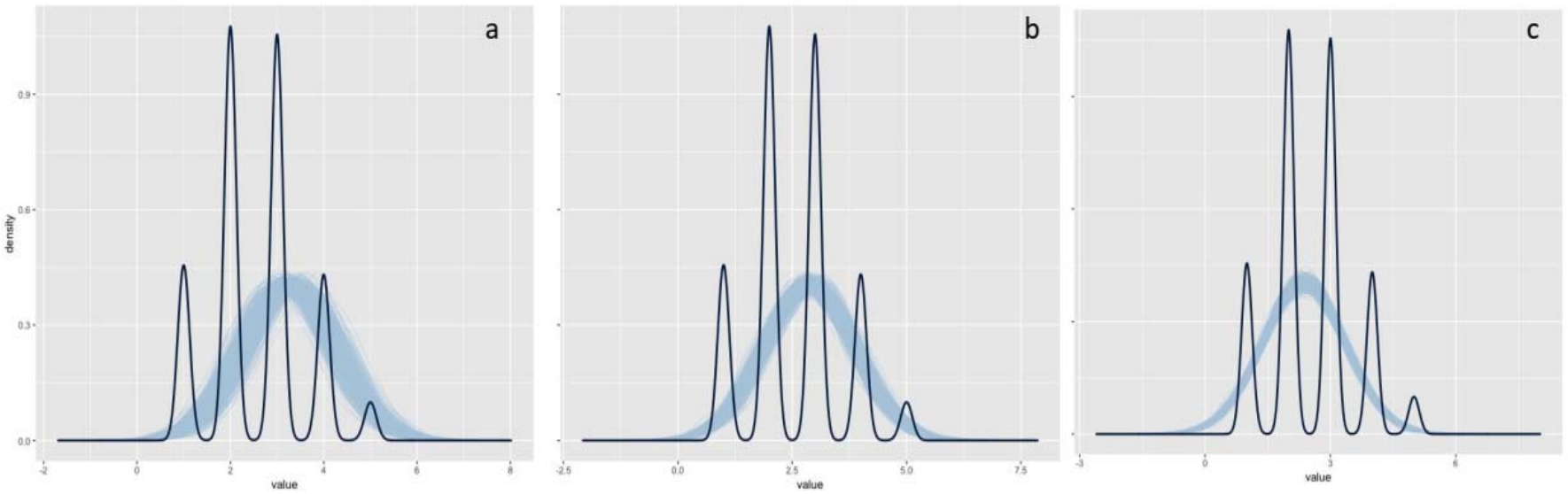

Figure 7. Predictions of students' academic achievements if: a) parents are non-manual labor workers; b) one parent does manual labor while other works in non-manual; and c) both parents are manual workers.

When the parents are all non-manual labor workers (Figure 7a), the values of prediction of students' academic results are converged toward category 3, which indicates average results. Meanwhile, when one parent does manual labor and the other works in non-manual (Figure 7b), the results are around categories 2 to 3 . Finally, as shown in Figure 7c, the academic achievement of students is predicted to be converged under category 2 when both parents work laborious jobs. The prediction somewhat confirms the Bayesian regression results.

\section{Discussion}

\section{Gender and academic performance in STEM subjects}

Firstly, the analysis shows that gender has little association with school results in STEM subjects (Fig. 1b). This goes against a common stereotype in a culture that views males as naturally more attracted to natural science and more capable at it than females (Leslie et al., 2015; Nosek et al., 2009). Even though the majority deliberately refuse the notion (Hyde et al., 1990), various studies verify the popularity of the "math = male" stereotype across multiple demographic factors including gender, age, and country (Cvencek et al., 2011; Kiefer and Sekaquaptewa, 2007; Nosek et al., 2009; Nosek et al., 2002). A substantial literature argues that these gendered differences are predominantly caused by unconscious bias and discrimination (Metcalf, 2018). Tackling individual and systemic bias is not easy, particularly in a discipline with a problematic history of marginalization like STEM (Metcalf, 2018). Therefore, the metaphor of a "leaky pipeline" is usually used to describe women's unequal attrition in STEM fields (Xie and Shauman, 2003; Correll, 2004; Cech et al., 2011). Although this study adds to the evidence of no performance difference in genders (Xie and Shauman, 2003; Hyde and Linn, 2006; Spelke, 2005); extant research still shows that common cultural stereotypes and biased practices in classroom and workplace devalue women's competence and creates environments that discourage female's pursuing and continuing STEM careers (Cech et al., 2011; Moss-Racusin et al., 2012; Fox, 2010; Reuben et al., 2014; Atir and Ferguson, 2018).

Moreover, parental resources tend to favor boys over girls in many Asian cultures (Lee, 2009; Hou and Leung, 2011), especially in a deeply Confucian culture such as Vietnam(Vuong et al., 2018a; Vuong and Tran, 2009; Napier and Vuong, 2013) in which men had more opportunities and privileges than women. 
Nevertheless, the findings reveal a "reverse gender gap" where girls are as academically capable as (or even more than) boys in terms of test scores and transition to higher education (Rolleston and lyer, 2019; Thanos et al., 2018). One explanation specific to rural areas might be the fact that boys face higher pressure of joining the labor market during adolescence as they are expected to shoulder the responsibility of earning for the family, therefore, have less interest in continuing their education. Gender norms also suggest that boys have the upper hand in the labor market to find better-paid jobs than girls. This could explain the higher motivation for learning and pursuing higher levels of education of female students, reflected by their outscoring in test results reported by some nationwide education investigations (Azubuike and Little, 2019). In other words, the reverse gender gap in Vietnam education might result from the reality that women have to work harder for the same outcomes compared to men.

Regarding the impact of gender in relation with SES on students' academic achievement, both genders yield positive values as illustrated, however, when examining the effect of gender in line with the parental occupation, female students are likely to outperform their male peers in STEM subjects, even more so when their parents are labors. The finding from this study is different from another one by Cheng et al. (2013). The latter indicated that gender effects are more evident in higher-educated families, which means that results of male students are better in Mathematics and Science than their female counterparts, and when considering education level of parents, boys tend to perform better in higher parental education families than lower ones (Cook et al., 1996; Entwisle et al., 2007; Zambrana et al., 2012). However, in this research, data analysis shows that female students are likely to have better academic achievements than their male peers in STEM subjects, even more so in disadvantaged SES situations.

\section{Socioeconomic status (SES) and STEM academic performance}

Secondly, the effect of family size was found discernible. Students having one sibling only seem to be of advantage compared to those with more than two siblings. This is in line with previous literature, according to which family size is detrimental to the intellectual development of children since parental resources are finite and become diluted with the expansion of sibship size (Blake, 1981). It further confirms the inverse relationship between sibship size and students' academic achievement (Powell and Werum, 2004; Downey, 2001). The negative effect of having an additional sibling on academic performance has been reported consistently across various operational definition of educational outcomes and in multiple settings including the United States (Blake, 1989; Downey, 1995; Kuo and Hauser, 1997), Europe (Wolter and Coradi Vellacott, 2002), Asia (Knodel and Wongsith, 1991; Anh et al., 1998; Post and Pong, 1998), and Africa (Lloyd and Brandon, 1992; Desai, 1995). However, larger sibship size is not necessarily correlated to lesser academic results in the context of some in some developing nations (Buchmann, 2000; Desai, 1995). The degree that additional siblings adversely influence learning scores may vary even among groups within one society because of their distinct characteristics, for instance, due to the support provided by the extended family for the nuclear family (Park, 2008). From policy perspectives, using international data on educational achievement among 15 -year-olds in 20 OECD countries, the study by Park (2008) demonstrates that nations characterized by better public support for childcare, universal child benefits, more public spending on education and family, show a far less adverse consequence of growing up in large families (Park, 2008). 
It is worth noting that current results also suggest that students having one sibling are of academic advantage compared to those without any sibling. Several studies have shown similar results; for example, lacavou (2001) reported that children with no siblings do worse than children in two-child families (lacovou, 2001). In a developing country context, Quian's (2009) study also found out that in the rural area of China, the only child has a disadvantage in school enrollment, and the benefit for bigger family size is larger for households where the children are of the same sex (Qian, 2009). Nevertheless, this is inconsistent with findings of various studies, for example, Cherian (1990) investigated the association between birth order and educational results of young people in Transkei, South Africa, and induced that first-borns and "onlies" benefit from a unique and favorable position in the South African families (Cherian, 1990). In this study, the reasons for this disadvantage of being the only child may result from various phenomena. First, the only child has neither an older brother/sister who serves as an intellectual source to stimulate cognitive development nor a younger sibling who gives the opportunities to take on the role of a "teacher" (Zajonc and Markus, 1975). As tutoring involves the reorganization and deep level processing of knowledge, having one (and not too many) younger sibling is considered favorable to a child's cognitive ability.

Furthermore, from a cultural perspective, parents and caregivers in Vietnam, like other Confucian societies, tend to be more concerned about physical needs and less disciplinary to their only child (Davin, 2017; Vuong et al., 2018a). To add on, the social aspect is the fact that parents with only one child in the countryside of Vietnam are more likely to leave home for job opportunities in urban areas, having their child taken care of by other relatives (GSO, 2016). Thus, lack of parental care and support due to domestic migration might negatively affect the only children's levels of academic achievement.

\section{Parent's occupation and STEM academic performance}

Thirdly, parent's education level and occupation type could also account for academic achievement. Data analysis shows that the education level of the parents is positively associated with the student's results. This is consistent with findings from numerous previous studies (Burušić et al., 2019; Kryst et al., 2015; Davis-Kean, 2005). In terms of parents' occupation, students have the propensity to achieve higher results if their parents worked in administrative or managerial positions. In other words, students whose one or both parents hold jobs that are considered 'skilled labor' tend to have better results than those born into households of manual labor workers. Studies have argued that discrepancies in socioeconomic contexts have long been identified as causes of individual disparities in cognitive ability (Noble et al., 2015). Factors such as educational backgrounds of parents and family income account for differences in brain regions crucial for the development of language, executive functions, and memory (Noble et al., 2015). Considerable IQ benefits are found both in the born and adopted children of more advantaged parents (Kendler et al., 2015). Accordingly, these findings have hinted and predicted the effect that home environment and parenting styles might have on children's cognitive development in less developed economic regions. In Confucian culture, those who did not have to do manual labor work were usually government officials, and as such, considered to be part of the intelligentsia. Such lettered people would be better resourced to provide their children with a scholarly culture as well as impose strict disciplines, manners, and etiquettes. All these would foster children's cognitive skills and cultural capital for academic success (Sikora et al., 2019; Evans et al., 2014).

\section{Conclusion}


An extensive literature has, for long, documented various determinants for students' academic achievement, particularly in STEM-related domains. We contribute to this literature by showing the associations between students' STEM education results against gender and socioeconomic factors. Bayesian statistical analyses of 4967 observations indicate that gender, family size as well as parental education and occupation all contribute to students' performance in STEM subjects to a varied extent. While gender has little association with the STEM results, female students are reportedly less vulnerable to SES effects than males. Results about family size demonstrate that having one sibling is favorable for a student compared to those with more than two siblings or without any, and being the only child in a rural family of a developing country is rather a disadvantage. The analyses show that parental educational level is positively associated with school results, and students tend to perform better if their parents are intellectuals. These results provide cultural insights into the role of SES and policy implications to bridge the social gap in education.

Given the apparent effects of SES factors despite the government's efforts to ensure equitable education, deeper levels of intervention are critical, such as enhancing school culture to narrow the SES gap in lower middle-income economies and promote the education of scientific knowledge to the general public (Vuong, 2018). Also, given the low enrollment rates of female students in STEM majors at universities despite their equal capability demonstrated in secondary school, measures need to be taken to encourage female participation in the tertiary level of STEM education to scale down the waste of labor resources.

In the context of transition economies, who are aiming to achieve the United Nation's Sustainable Development Goal by 2030, SDG4 - which focuses on inclusive, equitable and quality education - is among the top priorities (United Nations). To achieve this goal, STEM education is considered as a viable and holistic education approach (Linh, 2018; Thanh, 2018; Siemens Stiftung, 2019). This research offers robust empirical evidence of students' STEM education for scientists, policymakers, and other stakeholders in the developing countries and suggests lessons for future actions.

\section{Limitations of the study}

Despite the contribution to education policy in Vietnam, this study still has some limitations. Firstly, parent occupation types are much more varied, and the simplification of all these occupations into just two groups necessitated a lot of concessions. SES is based on self-reported measures by a child; it might not accurately reflect the situation since not all children are aware of their families' exact financial situation. The sample was chosen from a city in Northern Vietnam; therefore, the generalization to a wider population needs careful consideration.

\section{Figure legends}

Figure 1. The Bayesian regression model

Figure 2. The visual representation of the MCMC chains

Figure 3. Distribution of coefficients of variables that indicate the biological sex of the students.

Figure 4. Distribution of coefficients of $b$ (NumberofChi) and b(OnlyChi)

Figure 5. Distribution of coefficients of variables that indicate the economic status of the family and the education level of parents. 
Figure 6. Distribution of coefficients of variables that indicate the occupation of parents, in line with students' biological sex.

Figure 7. Predictions of students' academic achievements if: a) parents are non-manual labor workers; b) one parent does manual labor while other works in non-manual; and c) both parents are manual workers.

\section{Competing interests}

The author(s) declare no competing interests.

\section{Data availability}

The data is available in OSF. Identifier: DOI 10.17605/OSF.IO/CP35H; URL: https://osf.io/cp35h/

\section{Acknowledgments}

We would like to send our gratitude to the research staff of Vuong \& Associates (Hanoi, Vietnam) for assisting in collecting data, especially Do Thu Hang, Vuong Ha My, Ho Manh Tung, Nguyen To Hong Kong and Dam Thu Ha. Our most sincere appreciations also go on to personnel of junior high schools and provincial departments that provided support during the survey.

\section{References}

Anaya L, Stafford F P and Zamarro G (2017) Gender gaps in math performance, perceived mathematical ability and college stem education: The role of parental occupation.

Angrist J, Lavy V and Schlosser A (2010) Multiple experiments for the causal link between the quantity and quality of children. Journal of Labor Economics 28(4): 773-824.

Angrist J D, Lavy V and Schlosser A (2005) New evidence on the causal link between the quantity and quality of children: National Bureau of Economic Research (0898-2937.

Anh T S, Knodel J, Lam D and Friedman J (1998) Family size and children's education in Vietnam. Demography 35(1): 57-70.

Arauco V P, Molina G G, Aguilar E Y and Pozo W J (2014) Explaining low redistributive impact in Bolivia. Public Finance Review 42(3): 326-345.

Archer L, DeWitt J, Osborne J, Dillon J, Willis B and Wong B (2012) Science Aspirations, Capital, and Family Habitus: How Families Shape Children's Engagement and Identification With Science. American Educational Research Journal 49(5): 881-908.

Astone N M and McLanahan S S (1991) Family structure, parental practices and high school completion. American sociological review: 309-320.

Atir $\mathrm{S}$ and Ferguson M J (2018) How gender determines the way we speak about professionals. Proceedings of the National Academy of Sciences 115(28): 7278-7283.

Azubuike O B and Little A W (2019) Learning motivations, learning outcomes and gender in Vietnam.

Becker G S and Lewis H G (1973) On the Interaction between the Quantity and Quality of Children. Journal of Political Economy 81(2, Part 2): S279-S288.

Becker G S and Tomes N (1976) Child endowments and the quantity and quality of children. Journal of Political Economy 84(4, Part 2): S143-S162.

Behrman J R and Taubman P (1986) Birth order, schooling, and earnings. Journal of Labor Economics 4(3, Part 2): S121-S145.

Bergeson T (2006) Race, poverty, and academic achievement. Available on http://www.doh.wa.gov/SBOH/ESS/documents/Race\&Poverty.pdf. 
Betz N E and Hackett G (1981) The relationship of career-related self-efficacy expectations to perceived career options in college women and men. Journal of counseling psychology 28(5): 399.

Black S E, Devereux P J and Salvanes K G (2005) The more the merrier? The effect of family size and birth order on children's education. The Quarterly Journal of Economics 120(2): 669-700.

Blake J (1981) Family size and the quality of children. Demography 18(4): 421-442.

Blake J (1989) Family size and achievement. Univ of California Press.

Booth A L and Kee H J (2009) Birth order matters: the effect of family size and birth order on educational attainment. Journal of Population Economics 22(2): 367-397.

Breda T and Napp C (2019) Girls' comparative advantage in reading can largely explain the gender gap in math-related fields. Proceedings of the National Academy of Sciences 116(31): 15435-15440.

Buchmann C (2000) Family structure, parental perceptions, and child labor in Kenya: What factors determine who is enrolled in school? Social forces 78(4): 1349-1378.

Burušić J, Šimunović M and Šakić M (2019) Technology-based activities at home and STEM school achievement: the moderating effects of student gender and parental education. Research in Science \& Technological Education: 1-22.

Carnevale A P, Smith N and Strohl J (2013) Recovery: Job Growth And Education Requirements Through 2020: Georgetown University, Center on Education and the Workforce.

Caro D H, Cortina K S and Eccles J S (2015) Socioeconomic background, education, and labor force outcomes: evidence from a regional US sample. British Journal of Sociology of Education 36(6): 934-957.

Cech E, Rubineau B, Silbey S and Seron C (2011) Professional Role Confidence and Gendered Persistence in Engineering. American Sociological Review 76(5): 641-666.

Cech E A and Blair-Loy M (2019) The changing career trajectories of new parents in STEM. Proceedings of the National Academy of Sciences 116(10): 4182-4187.

Cook T D, Church M B, Ajanaku S, Shadish Jr W R, Kim J R and Cohen R (1996) The development of occupational aspirations and expectations among inner-city boys. Child development 67(6): 3368-3385.

Correll S J (2004) Constraints into Preferences: Gender, Status, and Emerging Career Aspirations. American Sociological Review 69(1): 93-113.

Cvencek D, Meltzoff A N and Greenwald A G (2011) Math-gender stereotypes in elementary school children. Child development 82(3): 766-779.

Chavez L F (2001) Access to advanced math for Latino high school graduates: The role of gatekeeping math courses. University of California, Berkeley.

Cheng C C, Wang W L, Sung Y T, Wang Y C, Su S Y and Li C Y (2013) Effect modification by parental education on the associations of birth order and gender with learning achievement in adolescents. Child: care, health and development 39(6): 894-902.

Cherian V I (1990) Birth order and academic achievement of children in Transkei. Psychological Reports 66(1): 19-24.

Davin D (2017) The early childhood education of the only child generation in urban China. Chinese Education. Routledge, pp. 42-65.

Davis-Kean P E (2005) The influence of parent education and family income on child achievement: the indirect role of parental expectations and the home environment. Journal of family psychology 19(2): 294.

Desai S (1995) When are children from large families disadvantaged? Evidence from cross-national analyses. Population Studies 49(2): 195-210.

Downey D B (1995) When bigger is not better: Family size, parental resources, and children's educational performance. American sociological review: 746-761. 
Downey D B (2001) Number of siblings and intellectual development: The resource dilution explanation. American psychologist 56(6-7): 497.

Eccles J S and Wigfield A (2002) Motivational beliefs, values, and goals. Annual review of psychology 53(1): 109-132.

Eilks I and Hofstein A (2014) Combining the question of the relevance of science education with the idea of education for sustainable development. Science education research and education for sustainable development: 3-14.

Entwisle D R, Alexander K L and Olson L S (2007) Early schooling: The handicap of being poor and male. Sociology of Education 80(2): 114-138.

Evans M D, Kelley J and Sikora J (2014) Scholarly culture and academic performance in 42 nations. Social Forces 92(4): 1573-1605.

Ferreira L M, Carosso G A, Duran N M, Bohorquez-Massud S V, Vaca-Diez G, Rivera-Betancourt LI, Rodriguez Y, Ordonez D G, Alatriste-Gonzalez D K and Vacaflores A (2019) Effective participatory science education in a diverse Latin American population. Palgrave Communications 5(1): 1-18.

Fouad N A (1995) Career linking: An intervention to promote math and science career awareness. Journal of Counseling \& Development 73(5): 527-534.

Fouad N A (2007) Work and vocational psychology: Theory, research, and applications. Annu. Rev. Psychol. 58: 543-564.

Fox M F (2010) Women and Men Faculty in Academic Science and Engineering: Social-Organizational Indicators and Implications. American Behavioral Scientist 53(7): 997-1012.

Gomes M (1984) Family size and educational attainment in Kenya. Population and Development Review: 647-660.

Goux D and Maurin E (2005) The effect of overcrowded housing on children's performance at school. Journal of Public Economics 89(5-6): 797-819.

GSO U (2016) The 2015 national internal migration survey: major findings.

Guo G and VanWey L K (1999) Sibship size and intellectual development: Is the relationship causal? American Sociological Review: 169-187.

Guo J, Marsh H W, Parker P D, Dicke T and Van Zanden B (2019) Countries, parental occupation, and girls' interest in science. The Lancet 393(10171): e6-e8.

Giannelli G C and Rapallini C (2017) The intergenerational transmission of math culture.

Harackiewicz J M, Rozek C S, Hulleman C S and Hyde J S (2012) Helping Parents to Motivate Adolescents in Mathematics and Science: An Experimental Test of a Utility-Value Intervention. Psychological Science 23(8): 899-906.

Hotz V J and Pantano J (2015) Strategic parenting, birth order, and school performance. Journal of population economics 28(4): 911-936.

Hou Z-j and Leung S A (2011) Vocational aspirations of Chinese high school students and their parents' expectations. Journal of Vocational Behavior 79(2): 349-360.

Hyde J S, Fennema E, Ryan M, Frost L A and Hopp C (1990) Gender comparisons of mathematics attitudes and affect: A meta-analysis. Psychology of women quarterly 14(3): 299-324.

Hyde J S and Linn M C (2006) Gender Similarities in Mathematics and Science. Science 314(5799): 599600.

lacovou M (2001) Family composition and children's educational outcomes: ISER Working Paper Series.

Kendler K S, Turkheimer E, Ohlsson H, Sundquist J and Sundquist K (2015) Family environment and the malleability of cognitive ability: A Swedish national home-reared and adopted-away cosibling control study. Proceedings of the National Academy of Sciences 112(15): 4612-4617.

Kenney-Benson G A, Pomerantz E M, Ryan A M and Patrick H (2006) Sex differences in math performance: The role of children's approach to schoolwork. Developmental Psychology 42(1): 11. 
Kessler D (1991) Birth order, family size, and achievement: Family structure and wage determination. Journal of Labor Economics 9(4): 413-426.

Kiefer A K and Sekaquaptewa D (2007) Implicit stereotypes, gender identification, and math-related outcomes: A prospective study of female college students. Psychological Science 18(1): 13-18.

Kim H S (2011) Consequences of parental divorce for child development. American sociological review 76(3): 487-511.

Knamiller G (1984) The struggle for relevance in science education in developing countries.

Knodel J and Wongsith M (1991) Family size and children's education in Thailand: Evidence from a national sample. Demography 28(1): 119-131.

Kremer M, Brannen C and Glennerster R (2013) The challenge of education and learning in the developing world. Science 340(6130): 297-300.

Kryst E L, Kotok S and Bodovski K (2015) Rural/urban disparities in science achievement in post-socialist countries: The evolving influence of socioeconomic status. Global Education Review 2(4).

Kuo H-H D and Hauser R M (1997) How does size of sibship matter? Family configuration and family effects on educational attainment. Social Science Research 26(1): 69-94.

La VP and Vuong QH (2019) bayesvl: Visually Learning the Graphical Structure of Bayesian Networks and Performing MCMC with 'Stan.' Available at: https://cran.r-

project.org/web/packages/bayesvl/index.html. (Version 0.8.5.)

Lee J (2008) Sibling size and investment in children's education: An Asian instrument. Journal of Population Economics 21(4): 855-875.

Lee K S (2009) Competition for resources: A reexamination of sibship composition models of parental investment. Journal of Marriage and Family 71(2): 263-277.

Leslie S-J, Cimpian A, Meyer M and Freeland E (2015) Expectations of brilliance underlie gender distributions across academic disciplines. Science 347(6219): 262-265.

Linh T (2018) 'General schools in Vietnam try STEM curricula,' Vietnamnet bridge. Available at: https://english.vietnamnet.vn/fms/education/210462/general-schools-in-vietnam-try-stemcurricula.html (Accessed: February 10, 2010).

Lloyd C B and Brandon A J (1992) Does sibsize matter? Implications of family size for children's educational opportunities and work responsibilities in Ghana.

Martins L and Veiga P (2010) Do inequalities in parents' education play an important role in PISA students' mathematics achievement test score disparities? Economics of Education Review 29(6): 1016-1033.

Metcalf H (2018) Creating a stronger STEM community by addressing our bias. Nat Hum Behav 2(8): 528529.

Miller J D and Kimmel L G (2012) Pathways to a STEMM Profession. Peabody Journal of Education 87(1): 26-45.

Moakler Jr M W and Kim M M (2014) College major choice in STEM: Revisiting confidence and demographic factors. The Career Development Quarterly 62(2): 128-142.

Moss-Racusin C A, Dovidio J F, Brescoll V L, Graham M J and Handelsman J (2012) Science faculty's subtle gender biases favor male students. Proceedings of the National Academy of Sciences 109(41): 16474-16479.

Author (2017): Chapter 3 - The Global Perspective. Available at: https://academic.microsoft.com/paper/2751717721.

Napier N K and Vuong Q-H (2013) What we see, why we worry, why we hope: Vietnam Going Forward. Boise, ID, USA: Boise State University CCI Press.

Noble K G, Houston S M, Brito N H, Bartsch H, Kan E, Kuperman J M, Akshoomoff N, Amaral D G, Bloss C $S$ and Libiger $O$ (2015) Family income, parental education and brain structure in children and adolescents. Nature Neuroscience 18(5): 773. 
Nosek B A, Banaji M R and Greenwald A G (2002) Math= male, me= female, therefore math $\neq$ me. Journal of personality and social psychology 83(1): 44.

Nosek B A, Smyth F L, Sriram N, Lindner N M, Devos T, Ayala A, Bar-Anan Y, Bergh R, Cai H and Gonsalkorale K (2009) National differences in gender-science stereotypes predict national sex differences in science and math achievement. Proceedings of the National Academy of Sciences 106(26): 10593-10597.

Park H (2008) Public policy and the effect of sibship size on educational achievement: A comparative study of 20 countries. Social Science Research 37(3): 874-887.

Pavitt K (1996) National policies for technical change: Where are the increasing returns to economic research? Proceedings of the National Academy of Sciences 93(23): 12693-12700.

Penner A M and Paret M (2008) Gender differences in mathematics achievement: Exploring the early grades and the extremes. Social Science Research 37(1): 239-253.

Pfeffer F T (2018) Growing Wealth Gaps in Education. Demography 55(3): 1033-1068.

Post D and Pong S-L (1998) The waning effect of sibship composition on school attainment in Hong Kong. Comparative Education Review 42(2): 99-117.

Powell B and Werum R (2004) Macro causes, micro effects: Linking public policy, family structure, and educational outcomes. After the Bell. Routledge, pp. 121-154.

Progress T N A o E (2018) The Nation's Report Card, United States. Available at: https://www.nationsreportcard.gov/tel 2018 highlights/.

Qian N (2009) Quantity-quality and the one-child policy: The only-child disadvantage in school enrollment in rural China: National Bureau of Economic Research.

Reardon S F (2011a) The widening academic achievement gap between the rich and the poor: New evidence and possible explanations. Whither opportunity 1(1): 91-116.

Reardon S F (2011b) The widening academic achievement gap between the rich and the poor: New evidence and possible explanations. In: Duncan, G.J. \& Murnane, R.J. (eds) Whither Opportunity. Russell Sage, pp. 91--116.

Reuben E, Sapienza P and Zingales L (2014) How stereotypes impair women's careers in science. Proceedings of the National Academy of Sciences 111(12): 4403-4408.

Robinson J P and Lubienski S T (2011) The development of gender achievement gaps in mathematics and reading during elementary and middle school: Examining direct cognitive assessments and teacher ratings. American Educational Research Journal 48(2): 268-302.

Rodríguez-Planas N and Nollenberger N (2018) Let the girls learn! It is not only about math... it's about gender social norms. Economics of Education Review 62: 230-253.

Rolleston C and lyer P (2019) Beyond the basics: Access and equity in the expansion of post-compulsory schooling in Vietnam. International Journal of Educational Development 66: 223-233.

Rosenzweig M R and Zhang J (2009) Do population control policies induce more human capital investment? Twins, birth weight and China's "one-child" policy. The Review of Economic Studies 76(3): 1149-1174.

Rozek C S, Ramirez G, Fine R D and Beilock S L (2019) Reducing socioeconomic disparities in the STEM pipeline through student emotion regulation. Proceedings of the National Academy of Sciences 116(5): 1553-1558.

Sax L J (1994) Mathematical self-concept: How college reinforces the gender gap. Research in Higher Education 35(2): 141-166.

Schneider B, Swanson C B and Riegle-Crumb C (1997) Opportunities For Learning: Course Sequences and Positional Advantages. Social Psychology of Education 2(1): 25-53.

Serpa S, Ferreira C M, Santos A I and Teixeira R (2018) Participatory action research in higher education training. Int'l J. Soc. Sci. Stud. 6: 1. 
Shettle C, Roey S, Mordica J, Perkins R, Nord C, Teodorovic J, Lyons M, Averett C, Kastberg D and Brown J (2007) The Nation's Report Card [TM]: America's High School Graduates. NCES 2007-467. National Center for Education Statistics.

Siemens Stiftung (2019) "Design Thinking in STEM": Education project combining STEM education, design-based education and the challenges addressed by the SDGs: Sustainable Development Goals Partnership Platform. Available at:

https://sustainabledevelopment.un.org/partnership/?p=35246 (Accessed: 20 Feb 2020).

Sikora J, Evans M and Kelley J (2019) Scholarly culture: How books in adolescence enhance adult literacy, numeracy and technology skills in 31 societies. Social science research 77: 1-15.

Sirin S R (2005) Socioeconomic Status and Academic Achievement: A Meta-Analytic Review of Research. Review of Educational Research 75(3): 417-453.

Sjaastad J (2012) Sources of Inspiration: The role of significant persons in young people's choice of science in higher education. International Journal of Science Education 34(10): 1615-1636.

Skorton D (2019) Branches from the same tree: The case for integration in higher education. Proceedings of the National Academy of Sciences 116(6): 1865.

Spelke E S (2005) Sex differences in intrinsic aptitude for mathematics and science?: a critical review. Am Psychol 60(9): 950-8.

Steelman LC, Powell B, Werum R and Carter S (2002) Reconsidering the effects of sibling configuration: Recent advances and challenges. Annual review of sociology 28(1): 243-269.

Sum A and Fogg W N (1991) The adolescent poor and the transition to early adulthood. Center for National Policy.

Takaoka S (2019) Vietnam's human capital: Remarkable education success and future challenges: World Bank.

Turner S L, Steward J C and Lapan R T (2004) Family Factors Associated With Sixth-Grade Adolescents' Math and Science Career Interests. The Career Development Quarterly 53(1): 41-52.

Thanos M, Van P and John S (2018) Puzzle me this?: The Vietnamese reverse gender education gap: World Institute for Development Economics Research (UNU-WIDER).

Thanh M (2018) 'STEM training booms but not in schools,' Vietnamnet Bridge. Available at: https://english.vietnamnet.vn/fms/education/204226/stem-training-booms-but-not-inschools.html (Accessed: February 10, 2010).

Trung Tran, Thi-Thu-Hien Le, Thu-Trang Nguyen, Anh-Giang Pham, Thi-Hanh Vu, Minh-Hoang Nguyen, Ha-My Vuong, Thu-Trang Vuong, Phuong-Hanh Hoang, Manh-Toan Ho and Quan-Hoang Vuong (2019) The Relationship between Birth Order, Sex, Home Scholarly Culture and Youths' Reading Practices in Promoting Lifelong Learning for Sustainable Development in Vietnam. Sustainability 11(16).

UNESCO (2015) UNESCO Science Report: towards 2030, Paris, France: United Nations Educational, Scientific and Cultural Organization.

United Nations Sustainable Development Goals: United Nations. Available at: https://sustainabledevelopment.un.org/ (Accessed: 20 Feb 2020).

Villarroel-Mareño M and Ergueta B IS (2012) Ranking mundial de universidades, la situación de la universidad boliviana World ranking of universities, the situation of the Bolivian University. BIOFARBO 20(1): 58-64.

Vuong Q-H (2018) The (ir)rational consideration of the cost of science in transition economies. Nature Human Behaviour 2(1): 5-5.

Vuong Q-H (2019a) Breaking barriers in publishing demands a proactive attitude. Nature Human Behaviour 3(10): 1034-1034.

Vuong Q-H (2019b) Computational entrepreneurship: from economic complexities to interdisciplinary research. Problems and Perspectives in Management 17(1): 117-129. 
Vuong Q-H (2019c) The harsh world of publishing in emerging regions and implications for editors and publishers: The case of Vietnam. Learned Publishing 32(4): 314-324.

Vuong Q-H, Bui Q-K, La V-P, Vuong T-T, Ho M-T, Nguyen H-K T, Nguyen H-N, Nghiem K-C P and Ho M-T (2019a) Cultural evolution in Vietnam's early 20th century: a Bayesian networks analysis of Franco-Chinese house designs. Social Sciences \& Humanities Open 1(1): 100001.

Vuong Q-H, Bui Q-K, La V-P, Vuong T-T, Nguyen V-H T, Ho M-T, Nguyen H-K T and Ho M-T (2018a) Cultural additivity: behavioural insights from the interaction of Confucianism, Buddhism and Taoism in folktales. Palgrave Communications 4(1): 143.

Vuong Q-H, La V-P, Vuong T-T, Ho M-T, Nguyen H-K T, Nguyen V-H, Pham H-H and Ho M-T (2018b) An open database of productivity in Vietnam's social sciences and humanities for public use. Scientific Data 5(1): 180188.

Vuong Q H, La V-P and Ho M-T (2019b) Vietnamese Junior High School Students' SES, Reading Preferences and Habits, and STEM Results Dataset: OSF. Available at: https://osf.io/cp35h/ (Accessed: 20 Feb 2020).

Vuong Q H and Tran D (2009) The Cultural Dimensions of the Vietnamese Private Entrepreneurship: ULB - Universite Libre de Bruxelles. Available at: https://EconPapers.repec.org/RePEc:sol:wpaper:09$\underline{027}$.

Wolter S C and Coradi Vellacott M (2002) Sibling rivalry: A look at Switzerland with PISA data.

Xie Y (2014) Is US science in decline? Issues in Science and Technology 30(3): 37-41.

Xie Y, Fang M and Shauman K (2015) STEM education. Annual review of sociology 41: 331-357.

Xie $Y$ and Shauman K (2003) Women in science: career processes and outcomes Harvard University Press. Zajonc R B and Markus G B (1975) Birth order and intellectual development. Psychological Review 82(1): 74.

Zambrana I M, Ystrom E and Pons F (2012) Impact of gender, maternal education, and birth order on the development of language comprehension: a longitudinal study from 18 to 36 months of age. Journal of Developmental \& Behavioral Pediatrics 33(2): 146-155.

Ziol-Guest K M and Lee K T H (2016) Parent Income-Based Gaps in Schooling: Cross-Cohort Trends in the NLSYs and the PSID. AERA Open 2(2): 2332858416645834. 